- Boston, Massachusetts, that is affiliated with health groups at Harvard University in Cambridge, Massachusetts. The group intends to launch its campaign in January 2012, says Louise Ivers, a senior adviser to $\mathrm{PIH}$ working in Haiti. The lack of clean water and sanitation in Haiti, and the poor prospects for improving that infrastructure in the near future, makes for a "compelling argument" to use cholera vaccines, she says.

The WHO opposed vaccination during the chaos of the initial cholera outbreak in Haiti; Claire-Lise Chaignat, coordinator of the WHO's Global Task Force on Cholera Control, argued at the time that the logistics would have been impossible to manage (see Nature 468, 483-484; 2010). But the chaos has subsided, and the peaks in numbers of cholera cases are coming less frequently, so the WHO now supports targeted vaccination in Haiti, says Chaignat.

Eventually, the Haitian government will have to assume responsibility and run its own vaccination programmes, but persuading them to do so could be tough, warns Van Herp - not least because there is little economic or political interest in the rural target communities that might benefit most. Van Herp and other experts also warn that cholera vaccination is no panacea. The focus of relief efforts must be on rehydrating the dangerously ill with a cheap and highly effective oral solution of glucose and salts, he says. Building infrastructure to provide clean water and sanitation is the only way to prevent cholera in the long term.

But a reduction in donor support for NGO frontline responders is hindering these efforts, says Pascale Zintzen, MSF's deputy head of mission in Haiti. "Different international groups dependent on donors are no longer receiving funds or having their funding renewed," she says. At the same time, the government's health ministry has been slow to launch projects with the funds it has already received, she complains. Ivers adds, "Over the past few months, we have seen a number of cholera treatment centres closing down."

Graaff says that Haiti needs to begin integrating routine cholera surveillance and treatment into the health services, moving away from its reliance on emergency response. Ivers argues, however, that the Haitian government is years away from being able to make that transition, and that continued support from NGOs is essential.

"I think it is a little misleading to suggest that it's OK that there is less support, because the government is somehow going to take over," she says. "Does it have the money, the supply chain and the human resources to provide the services that are needed? I don't think the ministry of health has any of those things." -

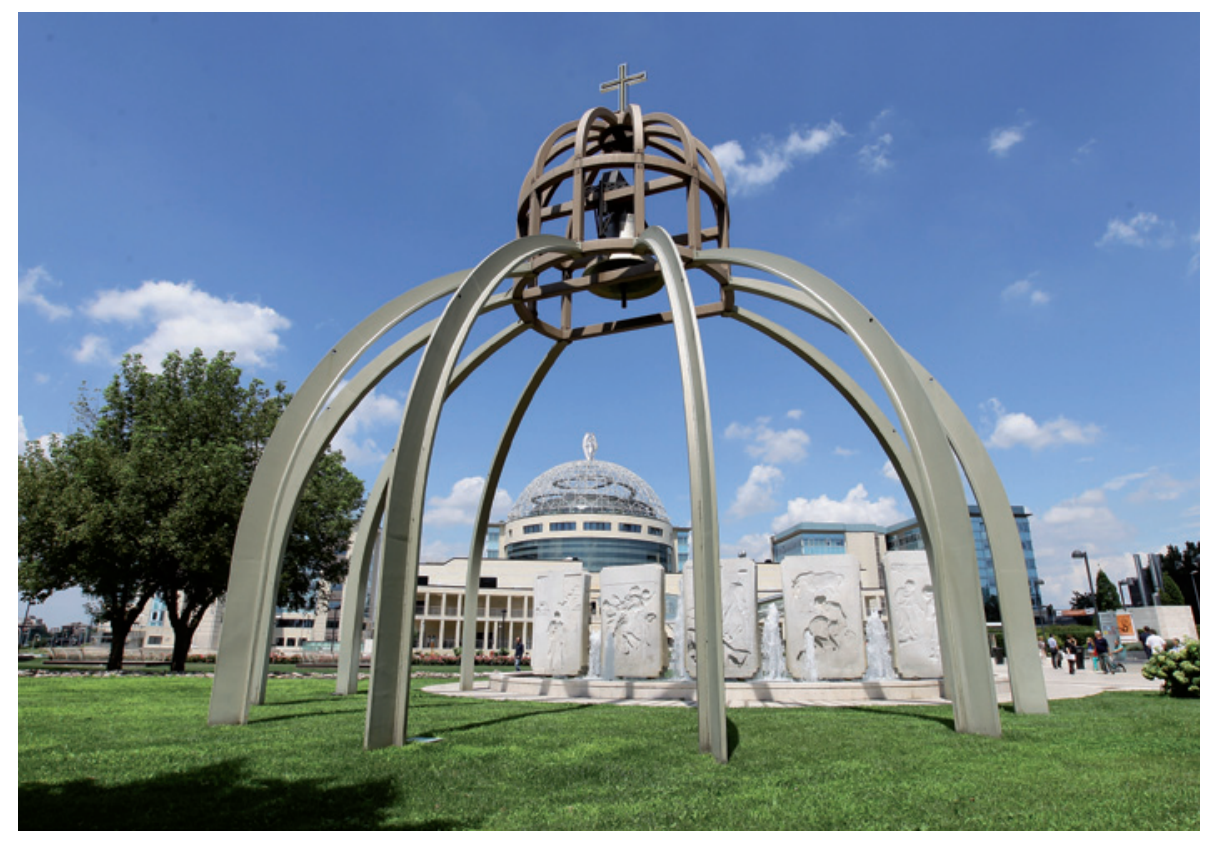

Milan's San Raffaele Scientific Institute may have to shut down if it can't be rescued from bankruptcy.

BIOMEDICAL RESEARCH

\title{
Vatican bids for Italian institute
}

\section{Debt and death hit San Raffaele research centre.}

\section{BY ALISON ABBOTT}

$\mathrm{O}$ ne of Italy's most prestigious biomedical research centres now faces bankruptcy, against a backdrop of rumours fed by intrigue among power-brokers, allegations of fraud and corruption, and a violent death. Next week, a court will decide whether to leave the Milan-based San Raffaele Scientific Institute to its fate, or allow a consortium led by the Vatican Bank to rescue it.

The institute, which includes a 1,400-bed research hospital, a basic-research centre and a small university, has run up debts approaching $€ 1.5$ billion (US $\$ 2.1$ billion). The debt has been attributed to poor investment decisions and overzealous expansion, and criminal investigations have begun into alleged corruption in the institute's financial dealings. Most granting agencies have now suspended payments to the scientists there, and many companies are no longer supplying consumables. "We are still working, but in low gear," says immunologist Maria Grazia Roncarolo, the institute's scientific director.

Scientists inside and outside Italy are appalled. "The San Raffaele is one of the most high-quality research centres in Italy, perhaps

in Europe," says Paul Herrling, chair of the institute's scientific advisory board and head of developing-world medicine at Novartis in Basel, Switzerland. "It has one of the best set-ups for gene therapy in the world - it needs to be saved."

The charismatic figure at the centre of the story is 91-year-old Luigi Maria Verzé, the Catholic priest who founded the hospital in 1971 and formally remains chair of the San Raffaele del Monte Tabor Foundation, which runs the institute. He added on a large building in 1992 to expand the facilities for basic research. In 1996, he founded a university on campus with three faculties - medicine, psychology and philosophy - in alignment with his belief that humans comprise body, mind and soul.

The San Raffaele Scientific Institute is nonetheless constitutionally secular, and Verzé has never imposed restrictions on research or teaching activities. His acknowledged skill in appointing productive scientists - frequently interviewing them himself - allowed the research centre, home to 221 permanent and

ONATURE.COM Nature's Italy portal: go.nature.com/uhmubt
332 contract scientists, to blossom.

Last year, the institute received $€ 75$ million in 
competitive research grants and $€ 18$ million in research funding from the Italian ministry of health, and published more than 800 scientific papers. It also carried out some 250 clinical protocols, half of which related to discoveries made in its own labs in areas such as gene and stem-cell therapy. It also has several large strategic partnerships with the pharmaceutical industry.

Verzé has exported his concept to 15 other countries, including the 500-bed São Rafael Hospital in Bahia, Brazil. In 2005, he began a major expansion programme at the Milan campus, constructing three large buildings for the research centre and university and for start-up companies, although scientists have yet to move into the latest of these facilities.

In February, newspapers first started to report on the institute's debts, then believed to be around half a million euros. "At first we weren't so worried because we thought it would sort itself out," says Giulio Cossu, director of San Raffaele's Stem Cells Research Institute.

But at the end of June, the debt was revealed to be closer to $€ 1$ billion. "We began to realize the situation was serious," says Cossu. The board of the San Raffaele del Monte Tabor Foundation was replaced and most of the executive power was transferred to its new vice-chair, Giuseppe Profiti, who is director of the Vatican's Paediatric Hospital of the Baby Jesus in Rome.

The situation soon worsened. On 18 July, Verzés right-hand man, Mario Cal, shot himself in his San Raffaele office. He died on an operating table at the hospital. Since then, Italian newspapers have reported that the foundation had invested heavily, and perhaps unwisely, in real estate, energy, various hotels and even a mango plantation.

The proposed rescue package is led by the Vatican Bank and a businessman, Vittorio Malacalza, who plan to absorb $€ 500$ million of debt and invest a further $€ 250$ million. The reason behind the Vatican's interest is unclear: Verzé has frequently been at odds with the Vatican over fundamental issues such as euthanasia, which

"The San Raffaele is at a dangerous crossroad." he does not regard as a sin.

The rescue consortium has told scientists at the San Raffaele that it plans to keep the research and hospital complex intact and shed investments unrelated to health. A Milan court will decide on 26 October whether the proposed investment and restructuring is sufficient to avoid bankruptcy.

The threatened bankruptcy means that most payments to the institute have been stopped. The frozen funds include millions of euros in grants from the European Union's Seventh Framework programme; the Italian
Association for Cancer Research, a charity based in Milan; and the European Research Council (ERC). The Telethon Foundation, however, a research charity in Rome that has approved grants worth $€ 7$ million, is now paying grantees directly, rather than through the institute.

One of the institute's seven ERC grantholders has been unable to begin his work; another has left; and a third is planning to do so, because of the problems, says Roncarolo. Late last month, representatives of computer manufacturer Hewlett Packard arrived at the institute's genomics centre to take back leased data-storage instrumentation until the finances are sorted out.

Although the institute's scientists are eager to be rescued, Roncarolo says that they are also worried about whether the new owners will understand that it is the mixture of basic and clinical science under one roof that makes the hospital so strong.

"The San Raffaele is at a dangerous crossroad," says Aaron Ciechanover, a Nobel laureate and chemist at Technion, Israel's Institute of Technology in Haifa, and a member of the San Raffaele's scientific advisory board. "I hope that the court will approve the rescue plan, and that the new owners will realize what a jewel they have and understand they need to keep the excellent research going." 